\title{
DESINTEGRAÇÃo E REPETIÇÃo: UMA ANÁLISE A PARTIR DE WILLIAM BASINSKI
}

\author{
Manuel Bogalheiro
}

\begin{abstract}
RESUMo
Partimos da peça musical Disintegration Loops de William Basinski. A obra, com cerca de uma hora de duração, é constituída por um ostinato que se deteriora até ao ruído e, por fim, ao silêncio. Basinski digitalizou o som de velhas bobines de loops feitas por si nos anos 80 para memória em disco; por força do pó e da oxidação, ao serem tocadas no leitor magnético as fitas começaram a degradar-se progressivamente. A reprodução do som, e o esforço para a sua preservação, implicou a sua destruição que, ainda assim, ficou gravada num novo meio. Questionam-se aqui os efeitos das migrações entre meios (analógico/digital) e a tensão entre a cristalização do simbólico pela técnica e a irredutível instabilização entrópica que daí resulta. A estrutura interna da peça acentua a noção de repetição como uma forma também instável e dinâmica que cria algo de novo. Esboça-se então uma crítica ao determinismo e ao automatismo que por vezes revestem a técnica e a tomam como um "círculo perfeito". O percorrer dessa circunferência, com o desgaste que lhe provoca e com as hesitações e os ritmos humanos, mostra que tal círculo não é perfeito e que a "desintegração" é, afinal, metáfora da natureza humana.
\end{abstract}

\section{Palavras-Chave}

Desintegração; determinismo; entropia; repetição; transcodificação; transdução

\begin{abstract}
Our starting point is the musical piece Disintegration Loops, by William Basinski. This work is about one hour long and consists in an ostinato that deteriorates into noise, and finally into silence. Basinski digitized the sound of old tape loops he had recorded in the 1980s, storing them in a computer drive; as the loops were played in the magnetic reader, they began to deteriorate due to the accumulation of dust and oxidation. The reproduction of the sound and the effort to preserve it led to its destruction, which was itself recorded into a new medium. The present article questions the effects of migrations between different media (analogue/digital) and the tension between the technical crystallization of symbolism and the inevitable entropic destabilization it generates. The internal structure of Basinski's piece highlights the notion of repetition as an equally unstable and dynamic form, which creates something new. It suggests, moreover, a criticism of the determinism and the automatism that sometimes take over the technical realm, regarded as a "perfect circle". Moving along this circumference, with the deterioration this gesture implies, and with the hesitation and the human rhythms it evokes, one realizes that the circle is not perfect, and that "disintegration" is ultimately a metaphor for human nature.
\end{abstract}

\section{KEYWORDS}

Determinism; disintegration; entropy; repetition; transcodification; transduction 
O tempo do mundo é o da irreversibilidade, e o da memória tempo da sua absolvição.

Gertrude Stein

É preciso então que nos resignemos a ser um relógio que mede a passagem do tempo, ora avariado, ora reparado, e cujo mecanismo gera desespero e amor assim que o seu criador o põe em marcha? Cresceremos nós habituados à ideia de que todo o homem revive as angústias antigas, que são ainda mais profundas porque se tornam mais ridículas com a repetição? Que a existência humana se deva repetir a si mesma, tanto melhor, mas que se repita como uma música vulgar, ou como um disco que um bêbado continua a tocar enquanto coloca moedas numa jukebox... Stanislaw Lem, Solaris

\section{TRANSCODIFICAÇÃo E IMPOSSIBILIDADE DA ESTABILIZAÇÃo}

William Basinski (1958, Texas, EUA) estudou jazz e música clássica (clarinete, saxofone e composição) antes de, no final dos anos 70, e influenciado por compositores como Steve Reich, Brian Eno ou Gavin Bryars, fazer as primeiras experiências de manipulação e de regravação de fitas de cassete, das quais extraía pequenos trechos musicais que organizava em composições repetitivas. Esta técnica experimental, baseada no trabalho da repetição e da apropriação de material sonoro já existente (found sounds), tornar-se-ia a sua principal forma de criação musical e cunharia uma estética própria, próxima do minimalismo ou da música drone, reconhecível pela textura ensombrada e pela cadência lânguida das curtas frases musicais que se repetem exaustivamente. Com mais de 20 álbuns editados até ao momento, Basinski sempre procurou sustentar uma relação direta entre o material musical produzido e o processo experimental de produção que usa. Esta relação directa entre método e resultado tem vindo a ser compreendida, pelo próprio e pela crítica, como um exercício que, tanto técnica como simbolicamente, configura uma experiência reflexiva sobre os temas do tempo, da memória, da corrosão, da perda, do desvanecimento, da fragilidade, da instabilidade ou da aleatoriedade.

Em 2002, William Basinski edita a primeira versão de Disintegration Loops, a obra mais marcante da sua carreira'. A peça musical, com cerca de uma hora de duração e constituída por um ostinato ${ }^{2}$ que se deteriora até ao silêncio à medida que vai sendo repetido, resultou de um processo de transcodificação do analógico para o digital: depois

\footnotetext{
' A peça ficaria profundamente ligada aos trágicos eventos do 11 de Setembro de 2001 em Nova lorque. Basinski explicara, aquando da edição de Desintegration Loops, que, coincidentemente, estava a acabar a produção da peça no dia dos ataques ao World Trade Center, tendo observado do terraço de sua casa em Brooklin a queda das torres enquanto ouvia a peça. O tom e a sonoridade, e o próprio processo de gravação que lhe dá origem, potenciaram a recepção da peça como um testemunho elegíaco desse evento traumático.

${ }^{2} \mathrm{Na}$ linguagem musical, um ostinato é um motivo ou um padrão musical que é persistentemente repetido, sem ou com ligeiras variações, ao longo de uma peça musical. A origem italiana da palavra não será aqui irrelevante, visto que deriva do que pode ser traduzido para português como "obstinado". Atualmente, o anglicanismo "loop" parece, pelo menos no domínio da cultura popular, estar a substituir o vocábulo de origem italiana.
} 
de ter encontrado gravações em fitas de bobine de loops de material orquestral, feitos por si nos anos 80 , Basinski propôs-se digitalizar o som das pequenas sequências repetitivas que estava gravado nas fitas para memória em disco. O que começa como uma simples gravação transforma-se numa paradoxal performance que ficaria registada: por força do pó e da oxidação, as fitas, ao serem tocadas no leitor magnético, começaram a degradar-se progressivamente, repetição após repetição, afectando o som ao ponto de a pequena sequência orquestral inicial não ser mais do que ruído e, por fim, silêncio. Em vez de parar a reprodução, ou de tentar tratar o ruído, Basinski deixou que o processo técnico assumisse livremente o controlo da imprevisível reconfiguração sonora e compreendeu essas anomalias como forças de composição, sabendo que apenas traindo - desintegrando - o original poderia criar algo de novo à medida que o registava. A reprodução do som implicou a sua destruição e aquilo que na nova gravação digital é percebido como "desintegração sonora", até ao ruído e ao silêncio, testemunha a "desintegração física" das fitas de bobine, até não serem mais do que farrapos magnéticos deteriorados. O movimento da repetição evidenciou a irreversibilidade de que tudo o que avança, tudo o "que passa e em passar consiste"3, se desgasta, se desintegra. O esforço para a preservação, através do correr da fita, implicou a passagem aniquiladora do tempo que, ainda assim, ficou gravada num novo meio, criando algo novo. Nas palavras do próprio Basinski:

quando a desintegração se completou, o corpo [das fitas] era simplesmente uma pequena faixa de plástico transparente com alguns acordes agarrados, a música tinha-se transformado em pó e sido dissolvida ao longo do correr da fita em pequenos montes e resquícios. No entanto, a essência, a memória da vida e da morte dessa música, tinha sido salva: gravada e recordada num novo meio. (Basinski, 2012)

A tensão emocional que Basinski extrai do processo de produção da peça musical não deixa de ser a imagem de uma certa indiscernibilidade do potencial simultaneamente criativo e destruidor da técnica. É essa imagem que inscreve na peça a marca cultural do contemporâneo enquanto momento que tanto permanece afectado pela ideia de perda, porventura em relação ao projecto moderno, como, num gesto de compensação, se oferece a inéditos e totalmente reconfiguradores modos de produção, de territorialização e de conquista - da macro-escala do espaço planetário à micro-escala do genoma humano. A peça de Basinski pode, nesse sentido, ser ouvida não apenas como o resultado de um processo de gravação, mas como um evento sonoro que, como um processo dinâmico, exemplifica, a cada vez que é reproduzido, os limites físicos e temporais que, necessariamente, condicionam os modos de produção e de conquista da experiência. $O$ som corporiza em si mesmo a entropia que sempre paira sobre qualquer tentativa de fixar o informe, o contínuo ou o instável. É a consciência desse impulso natural para a degradação que progressivamente é acentuada no ouvinte à medida que o som se expõe a si próprio até não ser mais do que o inaudível vestígio da sua forma inicial.

3 "A vida passa e em passar consiste". Verso do poema de Ruy Belo Esplendor na relva. Belo, R. (2009). Todos os poemas. Lisboa: Assírio \& Alvim. 
O processo técnico de transcodificação, do analógico para o digital, de que William Basinski se serve para produzir The Disintegration Loops, é decisivo no entendimento do alcance dos efeitos da obra. O que começa por estar em causa - e Basinski aponta para esse aspeto, mesmo que não estivesse plenamente consciente dele - é uma das mais fundamentais condições da teoria contemporânea dos média: a qualidade dos meios de registo, de reprodução e de transmissão para realizar um trabalho de constante aparecimento de outras configurações do real ou, dito de outro modo, a sua qualidade para introduzirem novas organizações sensíveis da matéria do mundo.

Recuando ao final do século XX ao aparecimento do fonógrafo, da fotografia, ou do cinema, e reconhecendo as suas migrações mútuas e o seu legado para a contemporaneidade, é desde logo evidente o profundo impacto que, enquanto meios técnicos, tiveram na forma como se passou a percepcionar o espaço e o tempo. Continuam a ecoar as seminais observações de Walter Benjamin sobre o problema, no seu ensaio sobre a obra de arte: "com o grande plano alarga-se o espaço, com o retardador o movimento" (Benjamin, 1936, p. 233), a propósito da máquina fotográfica, e, no que diz particularmente respeito ao tempo, "o retardador não se limita a trazer à luz conhecidos motivos do movimento, antes descobre, nestes conhecidos, outros totalmente desconhecidos" (Benjamin, 1936, p. 233). Por seu lado, a máquina cinematográfica, com a "sua dinamite do décimo de segundo", aumentaria a "compreensão da irreversibilidade que rege a nossa existência" (Benjamin, 1936, p. 233).

As novas expressões simbólicas produzidas pelos meios técnicos provavam a possibilidade de existência de uma plasticidade do real e mais evidentemente do tempo, um tempo que, através das novas reprodutibilidades de edição e de montagem, podia ser petrificado, estendido, retardado, condensado ou acelerado - um tempo que podia ser mobilizado, através dos meios auxiliares das máquinas através de "plongés e contreplongés, interrupções e imobilizações, retardador e acelerador, ampliação e redução", na criação desse império a que Benjamin chamou de "inconsciente óptico" (Benjamin, 1936, p. 234). Em suma, nestes gestos técnicos, em que a "aparelhagem penetra tão profundamente na realidade" (Benjamin, 1936, p. 228), esteve em causa não apenas a possibilidade de se conhecerem outras nuances de um real que passou a estar ao dispor da operacionalização dos meios, mas também a possibilidade de todos virem a ser, munidos de instrumentos de registo e de reprodução, operadores e transformadores de tudo o que podia ser tecnicamente apreendido à sua volta.

No entanto, esta plasticidade técnica, reconfiguradora do real e do tempo, não deixa de ser concomitante com um certo efeito de "cristalização" que os meios aplicam àquilo que captam. À sua natureza técnica é irredutível uma procura pela preservação e pela constituição do arquivo, procura que moveu Basinski, e o anseio de vencer o esquecimento ou, como escreveu André Bazin, também a propósito do cinema, de "salvar-se da efemeridade da vida através da perenização dos instantes" (Bazin, 1976, p. 81). Esta ação da determinação técnica do tempo, à margem da evolução totalizante dos dispositivos, parece então encerrar um certo tipo de paradoxo: quando se percebe que todos os meios se haveriam de tornar máquinas de estabilizar e de condensar o tempo, revela-se 
também que essa estabilização só se concretiza numa exploração plástica daquilo que foi cristalizado, ou seja, apenas se segura o tempo na condição de lhe poder inscrever um faseamento instável, um refazer permanente; o poder de o transformar num ser em devir que nasce da operacionalização técnica ${ }^{4}$. Voltando ao cinema, a repetição técnica dos 24 frames por segundo, naquilo que tem de estabilizador, desde logo pela própria mecânica rotativa, é a única forma de imprimir uma força - sempre variável, modulável e, em certa medida, falível - às imagens em movimento.

As sequências orquestrais em repetição de Disintegration Loops levam ao extremo a ilustração de que a estabilização técnica da matéria simbólica, neste caso estando em causa a sua própria preservação, implica inscrever-lhe uma dinâmica que antes não existia. Em certa medida, este aspeto já se manifestara quando Basinski gravara os excertos orquestrais em fita magnética nos anos 80 e os constituira como ostinati ou repetições, aplicando-lhe técnicas de corte e de recontextualização, mas acentuara-se ainda mais quando as transpusera para formato digital em 2001. O registo não significou a petrificação da matéria, antes a sua metamorfose contínua.

Um duplo movimento circular evidencia-se neste processo: a circularidade mecânica das bobines que desgasta o som contido nas fitas a cada repetição técnica e que, com a erosão que o tempo provoca nos materiais e naquilo que eles contêm, expõe novos motivos musicais; a circularidade estrutural da música de Basinki, que, a cada repetição formal, a cada loop, expõe o efeito da ação material dos meios sobre o sensível e mostra que a repetição, na lógica interna de uma peça, é origem de uma diferença criadora e não de uma redundância confinante. Como escreveu Søren Kierkegaard, "a dialéctica da repetição é fácil; porque aquilo que se repete foi, caso contrário não podia repetir-se, mas precisamente o facto de ter sido faz com que a repetição seja algo de novo" (Kierkegaard, 2009, p. 51) $)^{5}$.

Em Disintegration Loops, mecânica e estrutura, técnica e forma conjugam-se para insistirem na impossibilidade da estabilização das unidades, à partida, fechadas; no limite, insiste-se na impossibilidade de existir uma unidade perfeita e original. O processo técnico de transcodificação a que Basinski recorre, ao passar os loops musicais do analógico para o digital, vem expôr numa outra perspetiva a relação entre o minimalismo da forma, com os seus constrangimentos e delimitações, e a obstinação entrópica das

\footnotetext{
4 Também Basinski se refere a este aspeto. Numa entrevista concedida ao site Mountain*7, o músico explica: "Fiquei incrédulo com o que tinha acabado de acontecer e incrivelmente emocionado com toda a qualidade redentora do que tinha acabado de experienciar, como cada um desses loops se desintegrou à sua maneira e ao seu próprio ritmo, mas, apesar disso, a vida e a morte da sua melodia se salvaram num outro meio". Retirado de https://mountain7.co.uk/?/archives/236-William-Basinski-Interview.html.

${ }^{5}$ Como é sabido, Kierkegaard é um dos autores que serve de apoio à teoria da repetição de Gilles Deleuze e, correlativamente, à sua teoria do atual e do virtual, par conceptual que não deixa de ser pertinente para o que aqui discutimos. Nos termos da sua filosofia, se o atual corresponde ao resultado do devir e, portanto, à diferença, àquilo que de novo surge, o virtual corresponde, por coexistir com cada atual que surge, ao que se repete. Dito de outro modo, tudo o que surge como novo é o resultado de um processo de diferenciação, mas as virtualidades e as diferenças repetem-se, isto é, as tensões, os problemas, a tendência para devir-outro, a heterogénese. Neste sentido, a repetição não é relativa à mesma coisa, idêntica e semelhante, que acontece uma e outra vez, sem que nada se altere, mas é relativa à tendência para a alteração. A repetição apenas pode ser entendida através do seu par: repetir é reinventar e, assim, alterar a natureza das coisas para um estado diferente do que até então se desconhecia. Repetir é começar outra vez. É também neste sentido que a repetição nunca é um gesto redundante em relação ao que já foi, mas é sempre criador de diferença (Deleuze, 2000).
} 
suas unidades, na sua tendência para dinâmicas imprevisíveis e desgovernadas. Muita da música contemporânea insistiu nesta relação, notavelmente através de compositores como Steve Reich, ou Philip Glass. A montante continuará sempre a estar o inaugural Bolero de Maurice Ravel de 1928, a peça que mais terá popularizado a forma do ostinato. Quando comparadas, é evidente, as duas peças desenvolvem-se inversamente. Naquilo que em Ravel é movimento crescente para a explosão, em Basinski é movimento decrescente para a desintegração. Mas, para além da diferença inversa dos movimentos de cada peça, e é isto o essencial, poderá não existir uma verdadeira diferença entre aquilo que fica da explosão e aquilo que fica da desintegração, assumindo a ideia de que há a possibilidade de coincidência entre o início e o fim. Tanto uma peça como outra mostram como a simplicidade da forma e a sua aparente circunscrição podem produzir, através da instabilidade gerada pelas pequenas variações sempre em evolução, uma complexidade que se desenvolve à margem daquilo que inicialmente foi codificado. Como Deleuze e Guattari notam a propósito da peça de Ravel:

- Bolero é, levando isso quase à caricatura, o tipo de agenciamento maquínico que conserva o mínimo da forma para a levar à explosão. (...) As proliferações de pequenos motivos, as acumulações de pequenas notas que progridem cinemática e emocionalmente, que tomam uma forma simples e lhe juntam indicações de velocidade e permitem produzir relações dinâmicas extremamente complexas a partir de relações formais intrinsecamente simples. (Deleuze \& Guattari, 1980, p. 331)

\section{DA ENTROPIA À COEXISTÊNCIA DE NÍVEIS}

Numa aproximação a uma teoria dos sistemas, a peça de Basinski parece complexificar a cisão instituída pela diferença conceptual entre sistema aberto e sistema fechado. A prova da sua hibridez enquanto processo e objeto manifesta-se em dois aspetos complementares, nos quais se refletem a materialidade e o efeito (sonoro) da peça. Em primeiro lugar, manifesta-se enquanto prova da ação do ambiente físico e das condições exteriores que determinam a desintegração física das bobines e a reconfiguração do som. Neste sentido, o ato de reprodução/regravação é percebido como um processo, físico e químico, que intensifica os efeitos e que molda as formas sensíveis de uma materialidade de registo aparentemente fechada e determinada, abrindo-Ihe fissuras, expondo-lhe outras tonalidades, confrontando-a, em última instância, com a sua condição de possibilidade física. A lenta progressão dos primeiros indícios de degradação até à erosão final é a maior testemunha deste processo. Em segundo lugar, tal hibridez manifesta-se ao se compreender que, apesar de assumida como uma peça musical circular constituída pela repetição de um loop - condição que lhe confere um aparente equilíbrio estável numa espécie de isolamento formal interior -, é justamente pela sucessão contínua da repetição da mesma unidade, que afinal nunca é a mesma, que se evidencia a fragilidade e a instabilidade de tal formatação estrutural, a qual está em permanente reconstituição. 
A suposta rigidez da formalidade estrutural do loop não assegura um equilíbrio que impeça a trajetória insurreta das pequenas unidades, cuja repetição desvela a sua metamorfose sonora. Em síntese, tanto o seu lado performativo, de ser resultado de uma gravação que registou a destruição da sua antiga forma, como a sua estrutura interna refletem na peça as tensões constantes entre o que se pode definir como um sistema aberto e um sistema fechado. Por conseguinte, The Disintegration Loops aparece-nos também como um exercício que problematiza a mítica ideia de um equilíbrio perfeito imune a perturbações exteriores, em contraste com a ideia de entropia. Se qualquer ideia de equilíbrio perfeito se reclama de um ideal de completude, o que implica que dele nada de novo germine, pois na sua matriz todas as variáveis possíveis já estão teleologicamente dadas, tal sistema perfeito corresponde, em certa medida, a um sistema morto, corresponde a um sistema que não é passível de uma atualização ou de uma evolução através das quais se produza verdadeiramente o novo. Por seu lado, na peça de Basinski, o silêncio da erosão final não nos indica a morte desse sistema, mas antes nos dá conta da expressão viva de um trajeto entrópico que foi percorrido: a repetição de um ostinato, longe de se fechar em si mesma, acolheu as interferências exteriores para se renovar no caminho para uma instabilidade que se revela incerta, imprivisível e livre.

Esta ideia de repetição como figura dinâmica e transdutiva, como instância sempre em atualização a conjugar vários momentos, "num tempo que se desdobra a cada instante em presente e passado, presente que passa e passado que se conserva" (Deleuze, 1998, p. 103), presta-se a uma correspondência com a própria ideia de movimento, o qual, segundo Deleuze, "implica uma pluralidade de centros, uma superposição de perspectivas, uma imbricação de pontos de vista, uma coexistência de momentos que deformam essencialmente a percepção" (Deleuze, 2000, p. 121). Não se trata de, na lenta progressão da desintegração, se negar a existência de um curso em movimento, ou de uma sequenciação que essa mesma desintegração afirme como irreversível. Mas, a existir, tal sequenciação não é hierárquica e apenas traduz a passagem instável de um heterogéneo a um outro heterogéneo. Cada loop que se repete revela a sua relatividade em relação a todos os outros e mesmo os loops iniciais da peça de Basinski, menos desintegrados, apenas se definirão por uma diferença de nível em relação aos posteriores, visto que são esses que, justamente, já coexistem virtualmente com a desintegração que se vai atualizando pela repetição.

A instabilização expressa-se então pelo ritmo e pela diferença em que se articulam os vários presentes em faseamento numa ação contínua de uns sobre os outros, todos como causa e efeito de todos os outros. Em cada desintegração da peça de Basinski atuam os vários meios que, como Deleuze e Guattari notaram a propósito da noção de ritornelo (ritournelle ${ }^{6}$ ), constituem o objeto: um meio exterior relativo aos materiais; um meio interior relativo aos elementos constituintes e às substâncias compostas; um meio

\footnotetext{
${ }^{6} \mathrm{Na}$ música, o ritornelo refere-se ao refrão de uma peça, ao motivo que se repete em determinadas partes, podendo também ser considerada um ostinato. Deleuze e Guattari definiram-na como um "agenciamento territorial", "um conjunto de matérias de expressão que traçam um território" (Deleuze \& Guattari, 1980, p. 397) uma forma de demarcação e de organização, ilustrando-a, por exemplo, com o canto de um pássaro que marca assim o seu território.
} 
intermediário, relativo aos limites; um meio anexo, relativo às forças de energia (Deleuze \& Guattari, 1980). O que os loops de Basinski revelam é o papel que a repetição tem na sua própria estrutura enquanto força de diferença e de criação:

cada meio existe efectivamente pela repetição periódica, que não tem outro efeito a não ser o da produção de uma diferença através da qual ele passa a um outro meio. É a diferença que é rítmica e não a repetição que, no entanto, a produz. (Deleuze \& Guattari, 1980, p. 385)

Sob esta perspetiva, se houver suspeitas disso, ter-se-á de rejeitar nesta argumentação a noção de determinismo, um conceito que em certa medida está demasiado próximo do de automatismo. Gilbert Simondon foi um dos filósofos contemporâneos a sustentar uma das mais pertinentes críticas à tendência técnica - que pode hoje ser vista como uma herança da modernidade tecno-científica - do automatismo e dos sistemas pré-determinados. Como alternativa, a sua proposta baseia-se na premissa de que qualquer ténica ou objeto técnico será tão mais evoluído quanto maior for a sua margem de indeterminação e de contingência, assim como quanto maior for a sua margem de abertura à ação de elementos exteriores (Simondon, 2012). Nesse sentido, a sua teoria da técnica prevê máquinas, não autonomizadas ou automatizadas, mas auto-reguladas, isto é, com uma capacidade de reequilíbrio que lhes permita integrar novos comandos ou planos de funcionamento, assim como acidentes que obriguem a um reajustamento do seu funcionamento interno. Mais do que instâncias de produção ou de reprodução, as máquinas são, para Simondon, instâncias de transdução, ou seja, são complexos estruturais onde um tipo de energia se traduz, através de um jogo agonístico de tensões, num novo tipo de energia. A particularidade desta conceção - cuja influência é inegável na teoria da técnica de Deleuze e Guattari` - é que cada transdução energética integra um vasto curso de outras transduções, como uma génese na qual "cada código está em estado perpétuo de transcodificação" (Deleuze \& Guattari, 1980, p. 384). Nesta génese, as máquinas são centros de indeterminação que, simultaneamente, prolongam e inauguram relações, energias e processos que derivam ou serão integrados pela rede das outras máquinas.

É tendo por base este quadro que Simondon considera que mesmo os meios técnicos de registo denotam um certo tipo de plasticidade indeterminada. Se, no que toca à memória humana, está em causa a plasticidade das formas - no tratamento subjetivo

\footnotetext{
7 A partir do campo disciplinar da biologia e do estudo da evolução dos cristais, Gilbert Simondon define da seguinte forma o conceito de transdução: "este termo denota um processo no qual uma actividade se define gradualmente em movimento, propagando-se num determinado domínio, ao basear a sua propagação numa estruturação realizada em diferentes zonas do domínio: cada região da estrutura constituída serve como um princípio constituído para o próximo, de modo a que uma modificação progressiva se estenda a si mesma, ao mesmo tempo desta operação estruturadora. A operação transdutiva é uma individuação em progresso; ela pode ocorrer fisicamente na forma de uma repetição progressiva." (Simondon, 2013, p. 32). Ainda que a sua definição não expresse directamente a relação do conceito com a sua teoria da técnica, é dessa conceção que resultam alguns dos princípios essenciais que Simondon projeta nos objetos técnicos: abertura, reação, feedback, ressonância interna, modificação e repetição progressivas, etc. Reconhecendo a influência de Simondon, podemos encontrar em Deleuze e Guattari algumas passagens que atualizam o conceito: "cada meio é codificado, um código define-se pela repetição periódica; mas cada código está em estado perpétuo de transcodificação, ou de transdução. A transcodificação, ou a transdução é a maneira pela qual um meio serve de base a um outro ou, ao contrário, se estabelece sobre um outro, se dissipa ou se constitui num outro" (Deleuze \& Guattari, 1980, p. 384).
} 
de esquemas, de imagens, de impressões ou de unidades percetivas, através da sua seleção, hierarquização, organização ou, em suma, através da produção de sentido que se faz a partir desses esquemas -, no que toca a uma memória das máquinas, sobretudo evidente nos meios de registo, está em causa a plasticidade do próprio suporte, naquilo que de variável está implicado na codificação e na tradução de formas operadas pelo meio (Simondon, 2012, pp. 168-170).

Voltando à peça de Basinski, poderemos agora afirmar que nela se conjugam e se refletem paradigmaticamente estas duas dimensões, a da plasticidade das formas e a da plasticidade do suporte. Mas, para além disto, poderemos também reforçar a ideia de que a conjugação destes dois tipos de plasticidade orienta a relação do indivíduo com o material simbólico que regista e reproduz através dos meios técnicos, sendo que, tanto pelo lado das formas, como pelo lado dos suportes, existe um certo grau de inconstância e de vulnerabilidade; dito de outro modo, tanto a memória dos homens como a memória das máquinas está sujeita ao mesmo tipo de processos de degradação, de adulteração, de transformação e de perda.

Nestes termos, não é, assim, determinista a ação dos meios, enquanto dispositivos de registo e de transcodificação, na passagem do analógico para o digital, como também não é determinista a própria estrutura interna em repetição de Disintegration Loops. Em oposição a essa ideia de determinismo, estaremos mais próximos de um conceito como o de destino, tal como Deleuze o entendeu em Diferença e Repetição:

o destino não consiste em relações de determinismo, que se estabelecem pouco a pouco, entre presentes que se sucedem conforme a ordem de um tempo representado. Entre os presentes sucessivos, o destino implica ligações não localizáveis, acções à distância, sistemas de retomada, de ressonância e de ecos, de acasos objectivos, de sinais e signos, de papéis que transcendem as situações espaciais e as sucessões temporais. Dos presentes que se sucedem e exprimem um destino, dir-se-ía que eles vivem sempre a mesma coisa, a mesma história, apenas com uma diferença de nível: aqui mais ou menos descontraído, ali mais ou menos contraído. Eis porque o destino se concilia tão mal com o determinismo, mas tão bem com a liberdade: a liberdade é de escolher o nível. A sucessão dos actuais presentes é apenas a manifestação de alguma coisa mais profunda: a maneira pela qual cada um retoma toda a vida, mas a um nível, ou grau diferente do precedente, todos os níveis ou graus coexistindo e se oferecendo à nossa escolha, do fundo de um passado que jamais foi presente. (Deleuze, 2000, pp. 160-161)

\section{A tÉCNICA COMO CÍRCULO PERFEITO DESINTEGRA-SE PELA AÇÃo DO RITMO}

A negação do determinismo, ou a possibilidade da escolha de nível, parece, contudo, ser estranha ao paradigma pós-fordista em que os computadores absorveram a 
lógica da rotação mecânica e da cadeia de montagem para a transformar numa estrutura binária através de uma lógica codificada. Numa perspetiva arqueológica dos meios, Lev Manovich relembra o seguinte:

- loop deu origem não apenas ao cinema, mas também à programação computacional. A programação envolve a alteração de fluxos lineares de dados através de estruturas de controlo como "se/então" e "repete/enquanto"; o loop é a mais elementar destas estruturas de controlo. A maior parte dos programas de computador são baseados em repetições de um número estabelecido de passos; esta repetição é controlada pelo loop dominante do programa. Portanto, se despirmos o computador do seu interface habitual e seguirmos a execução de um programa de computador típico, o computador revelar-se-á uma outra versão da fábrica fordista, com um loop enquanto correia transportadora. (Manovich, 2000, p. 266).

A concretização da informática computacional, à medida que integrou e absorveu todos os anteriores processos materiais e industriais, foi também a concretização de toda a técnica transformada em matemática realizada, em lógica aplicada. A importância civilizacional deste passo, a colonização pelo conceito numérico e a conquista da possibilidade de se poder trabalhar matematicamente o real, terá sido a de nos ter aproximado da dominação da contingência, de se poder filtrar, a todo o momento, o acaso através das probabilidades estatísticas e das sequências lógicas pré-determinadas. As escolhas de níveis parecem ter ficado reduzidas às opções já existentes no código que é tão mais eficiente quanto mais binário e mais circular, ou seja, mais simples, for. Percebe-se então uma indissociabilidade entre controlo e matemática. Em última instância, a máquina universal da segurança máxima corresponderia à totalidade de um cosmos que já não teria acidentes ${ }^{8}$.

A relação entre a tendência para a matematização do real e a figura da circularidade (na qual também está compreendida a ideia de repetição) pode ser desenvolvida em dois aspetos. O primeiro aspeto é de que há uma natureza essencial no gesto mecânico - e, consequentemente, no automatismo do cálculo - que se constitui como repetição. No documentário Wie man sieht de 1986, Harun Farocki ${ }^{9}$, depois de afirmar que na Revolução Industrial "a regularidade circular da máquina envergonhou a mão insegura do trabalhador", nota que com o "tear de Jacquard, que é controlado por cartões perfurados

\footnotetext{
${ }^{8}$ No seu tratado de 1932 sobre a figura contemporânea do trabalhador e a correlacionada mobilização total do mundo por via da técnica, o alemão Ernst Jünger especula, em vários momentos, sobre a possível concretização de um espaço tecnocrático com esse tipo de características: "O próprio desconhecido, o insolucionado torna-se calculável - ou seja, na medida em que se torna possível um plano e um prognóstico das soluções. (...) O espaço técnico ganha em clareza, organização e planificação e as soluções parciais já não são felizes achados, mas resultados da marcha ordenada de um tempo cada vez mais calculável" (Jünger, 2000, pp. 170-175).

${ }^{9}$ Harun Farocki (República Checa, 1944 - Alemanha, 2014) foi um dos realizadores mais marcantes e mais interpelantes do cinema documental e experimental. A sua vasta obra cinematográfica - marcada desde o início pela relação entre a mediatização da guerra e a existência de um espectador formado por essa mediatização - constitui uma incontornável reflexão sobre o estatuto das imagens na contemporaneidade, sobre a tensão entre o seu caráter real e o seu caráter ficcional ou sobre o papel da tecnologia na formação do olhar.
} 
como os que se usam nas calculadoras, a matemática passou a controlar o trabalho da mão". Na procura arqueológica de Farocki, a tendência para a matematização e para o controlo remete para uma certa relação primária dos meios técnicos com o movimento - circular ou repetitivo - da rotação. Depois do fogo, a roda terá sido o invento técnico mais importante da humanidade. Não apenas definiu o sentido do progresso material, desde os primeiros transportes ao paradigma da roda dentada ou do tear, como definiu também o sentido da sua perceção da realidade e do mundo. É neste sentido que, mais à frente, o realizador acrescenta o seguinte:

o movimento giratório proporcionou o pré-requisito para a produção contínua. Diz-se que o movimento dos planetas serviu de protótipo para o movimento da roda de fiar. Mas eu prefiro dizer: é porque os humanos já tinham inventado o torno que puderam reconhecer o movimento dos planetas. (Farocki, 1986)

Esta passagem permite-nos introduzir o segundo aspeto da relação entre a tendência para a matematização e a repetição ou a circularidade. Condicionada a perceção do espaço-tempo e da imagem do mundo pelos tornos da técnica, a evolução para a racionalização e para o aparelhamento gerais da realidade e do sensível construiu uma imagem que atualiza a velha utopia da positividade absoluta como circunferência fechada: a razão, a ciência e o formalismo, que sustenta as duas primeiras, como um círculo perfeito, um círculo de segurança. Tudo funciona lá dentro contra as irregularidades do humano. A procura pelo traçar do círculo apresenta as características da já referida noção de ritornelo como um agenciamento territorial em que se procura passar do caos à ordem: "nas obras sublimes como a fundação de uma cidade ou a construção de um Golem $^{10}$, traçamos um círculo, mas, sobretudo, caminhamos em torno desse círculo" (Deleuze \& Guattari, 1980, p. 382). Este último aspeto de "caminharmos em torno desse círculo" parece ser decisivo para contrariar a natureza totalizante desse mesmo círculo

\footnotetext{
${ }^{10}$ Não deixa aqui de nos ser de especial interesse a referência de Deleuze à figura lendária do Golem. Ancorada na mitologia cabalista do judaísmo, e em certa medida devedora do mito grego de Prometeu, a figura do Golem remete para a criação humana de uma réplica sua artificial. Numa imitação do gesto divino da criação, o indivíduo produziria a forma de um homem em barro, conferindo-lhe vida para o substituir em determinadas tarefas domésticas ou de risco. Nalgumas versões, o Golem não consegue agir por si próprio e apenas compreende as ordens que lhe são dadas; noutras, consegue autonomizar-se e acaba por se rebelar contra o seu criador humano; nesta segunda versão, o Golem representa a primeira figura da famosa teoria da alienação. A pertinência da atualidade desta narrativa mitológica mantém-se pela evidente genealogia da figura do robot, ou do andróide mas, sobretudo, por ser possível continuar a reconhecê-la como uma das principais inaugurações da conceção de artificial - o Golem problematiza a tensão entre a exterioridade daquilo que o homem cria e aquilo que no criado é irredutivelmente produto humano. No fundo, trata-se da tensão entre homem e cultura, considerando esta uma artificialização da experiência, ou da inconciliação entre homem e técnica. O Golem oscila entre a lógica do controlo e da servidão, ou do automatismo, e a lógica da autonomização, ou da inteligência artificial auto-generativa criadora de novas linguagens e de novas abstrações. O seu poder especulativo advém desta indefinição entre ser réplica e ser replicante, para nos socorrermos da terminologia de Philip K. Dick em Do Androids Dream With Electric Sheep? (1968). Enquanto repetição do humano, o Golem é símbolo da técnica mais complexa (daí que não tenha sido por acaso que Deleuze o refere para ilustrar a criação das "obras mais sublimes") enformando, a circunferência total da perfeição. Mas, tal como os loops que se actualizam no seu movimento, o Golem não só evidencia que o gesto para a repetição é sempre criação de algo novo e distinto, como o desgaste do seu agir mostra a impossibilidade do estado técnico perfeito, revelando o Golem como falsa repetição: ou se desintegra por estar condenado a não conseguir agir por si próprio ou se desintegra por abrir um processo de confronto com o seu criador.
} 
técnico: é pelo facto de percorrermos o perímetro do círculo, à partida perfeito, de repetirmos o curso desse movimento na procura da ordem que o forçamos ao desgaste, revelando assim a ficção que é a suposição da sua perfeição. A razão desse desgaste assenta no movimento da repetição incessante, mas também no facto de o movimento de caminharmos em torno do círculo ser ritmado e variável, de poder implicar a improvisação ou a falha. A peça de Basinski coloca-nos justamente na linha da circunferência que se desintegra irreversivelmente perante as ligeiras indeterminações e imprevisibilidades que se vão atualizando sem regra com o correr da fita magnética e com o curso da estrutura interna da música. É aí que tomamos conta de que a circunferência é cada vez menos perfeita e menos fechada. A circunferência já não pode ser positivista ou determinista porque, ao ser mobilizada pelo curso daquilo que avança, não segue a "medida que é dogmática mas antes o ritmo que é crítico" (Deleuze \& Guattari, 1980, p. 385) - o ritmo é criativo. $O$ indeterminismo ritmado do círculo, isto é, a sua imprevisibilidade, ou a sua improvisação fazem com que o "círculo tenda, ele mesmo, ao se abrir sobre um futuro, a reunir-se com as forças do porvir. Improvisar é encontrar o mundo, é confundir-se com ele" (Deleuze \& Guattari, 1980, p. 385). O ruído e o silêncio finais da peça de Basinski são a prova da presença de mundo que foi inscrita naquele objeto simbólico.

\section{E TUDO O RESTO É RUÍDO OU A IMPOSSIBILIDADE DO LOOP ORIGINAL}

O acaso que ameaça a circunferência está inscrito na possibilidade de se poder desconfiar de que, afinal, não estamos perante uma circunferência cumprida. Existirá uma escapatória à imagem do círculo perfeito que a técnica impôs ao real com vista a determiná-lo. Haverá porventura uma exterioridade desse círculo. Por um lado, tal exterioridade corresponde ao campo fértil a partir do qual podem desabrochar outros modelos explicativos do real que constituam uma alternativa ao positivismo científico. Por outro lado, essa exterioridade é a lembrança constante de que podemos pensar a possibilidade de articulação de todo o simbólico.

Todo o movimento, apesar da ilusão de continuidade que possa dar, é um ato de desintegração em partes, um ato de perturbação no qual as diferenças se instalam para atualizar virtualidades. É esse movimento irreversível que percorre o círculo, criando descontinuidades e forçando a técnica a abrir a circunferência sem que, no entanto e irredutivelmente, abdique dela. Disintegration Loops é a imagem sonora de tal possibilidade, a imagem de uma suspensão do desejo e de uma alternativa à aceleração que impõe a sua circularidade viciosa. Assumido que o registo pelos meios encerra as mesmas vulnerabilidades que afetam a memória humana, no fim, prefere-se a elegia do que podia ter sido à certeza científica do que se pode recolher. A repetição enquanto desintegração é, então, metáfora das variações, das imprevisibilidades, dos desgastes, das hesitações ou das demoras que, afinal, permitem a acção humana e as suas escolhas de nível. Porque o que persiste depois da suposta morte dos loops de Basinski é tudo aquilo que o mundo Ihe acrescentou de erosivo, de brutal, de confuso e de disforme, ou seja, tudo o que prova a impossibilidade de um loop original: instância imaculada que, na verdade, nunca o poderia ter sido. 


\section{REFERÊNCIAS BIBLIOGRÁFICAS}

Bazin, A. (1976). Qu'est-ce que le cinéma? Paris: Cerf.

Benjamin, W. (2004). A obra de arte na época da sua possibilidade de reprodução técnica. In W. Benjamin, A Modernidade (pp. 207-241). Lisboa: Assírio \& Alvim.

Deleuze, G. (2000). Diferença e repetição. Lisboa: Relógio d’Água.

Deleuze, G. (1998). Cinéma 2 - L'image-temps. Paris: Les Éditions de Minuit.

Deleuze, G. \& Félix G. (1980). Mille Plateaux. Paris: Les Éditions de Minuit.

Jünger, E. (2000). O trabalhador: domínio e figura. Lisboa: Hugin Editores.

Kierkegaard, S. (2009) A repetição. Lisboa: Relógio d’Água.

Manovich, L. (2000). The language of new media. Cambridge (Mass.): MIT Pre.

Simondon, G. (2012). Le mode d'existence des objets techniques. Paris: Aubier.

Simondon, G. (2013). L'individuation à la lumière des notions de forme et d'information. Paris: Editions Jérôme Million.

Wienner, N. (1998). The human use of human beings: cybernetics and society. Da Capo Press.

\section{FiLMOgRAFIA}

Farocki, H. (1986). Wie man sieht.

\section{MúsICA}

Basinski, W. (2002). The Disintegration Loops.

Ravel, M. (1928). Bolero.

\section{NotA BIOGRÁFICA}

Manuel Bogalheiro é professor na Faculdade de Comunicação, Artes, Arquitectura e Tecnologias da Informação da Universidade Lusófona do Porto, na qual dirige o Doutoramento em Arte dos Média. É doutorado em Ciências da Comunicação, especialidade de Cultura Contemporânea e Novas Tecnologias (FCSH-UNL), com uma tese intitulada "Materialidade e Tecnicidade: investigação sobre a objectualidade técnica", tendo sido bolseiro FCT. É investigador integrado no Centro de Investigação em Comunicação Aplicada, Cultura e Novas Tecnologias (CICANT). Investiga e publica nas áreas da filosofia da técnica, da teoria dos média e da cultura.

E-mail: manuel.bogalheiro@gmail.com

Morada: Universidade Lusófona do Porto, Rua de Augusto Rosa 24, 4000-098 Porto (Portugal) 


\section{* Submetido: 30-11-2017}

* Aceite: 15-02-2018 